\title{
Las restricciones de selección en los diccionarios generales de lengua española*
}

\author{
Susana Serra Sepúlveda** \\ Universidad de Chile
}

\begin{abstract}
Resumen
Las primeras formulaciones sobre restricciones de selección en lingüística corresponden a la Teoría Estándar de la Gramática Generativa (1965), pero, tal como se las entendió entonces, poseían un valor fundamentalmente extralingüístico (se trataba de nociones tales como 'animado', 'humano', 'cosa', 'instrumento', etc.). En este trabajo, se muestra cómo el concepto tradicional de "selección" se ha enriquecido con la incorporación de nuevos rasgos, tanto semánticos como categoriales, provenientes de la léxico-sintaxis. En este contexto, son especialmente importantes DICE (Diccionario de Colocaciones del Español, en proceso) y REDES (2004), dos diccionarios onomasiológicos del español contemporáneo, que se diferencian justamente por el modo de entender (y tratar) la "direccionalidad" de la selección léxica. El estudio se complementa con el análisis de las restricciones de selección observadas en los contornos de las definiciones lexicográficas de los diccionarios semasiológicos del español actual. Tal análisis muestra que las llamadas "colocaciones"
\end{abstract}

* Este trabajo forma parte de mi tesis doctoral que aborda las relaciones entre la gramática y el diccionario.

** Para correspondencia dirigirse a: Susana Serra (sserra@uchile.cl), Departamento de Lingüística, Facultad de Filosofía y Humanidades, Universidad de Chile, Ignacio Carrera Pinto 1025, Tercer Piso, Ñuñoa, Santiago. 
no difieren en su comportamiento semántico-sintáctico del resto de las combinaciones sintagmáticas de la lengua, en la medida en que en ellas el proceso de selección entre los colocados parece responder a la orientación predicado $>$ argumento.

Palabras clave: combinatoria léxica, restricciones de selección, colocaciones, contornos lexicográficos, predicados y argumentos.

\title{
LeXicAl ReStrictions IN THE SPANiSh language GeNERAL DICTIONARIES
}

\begin{abstract}
The first formulation on restrictions on lexical insertion is to be found in generative grammar's Standard Theory (1965). However, as then understood, restrictions had a basically extralinguistic value (concerning notions such as 'animate', 'human, 'thing', 'instrument', etc.). This paper shows how the traditional concept of selection has been enhanced by the incorporation of new features, whether semantic of categorical, from the Hispanic research tradition on the field of lexical syntax. Particularly worthy of mentioning to this respect are two onomasiological dictionaries of contemporary Spanish, which differ from one another by the directionality of lexical selection. Aditionally, an analysis of selectional restriction observed in the 'entourage' of lexical definitions from current semsiological Spanish dictionaries. Such analysis shows that the collocations do not differ in their syntactic-semantic behavior from the rest of language, inasmuch as the process of selection between the allocated seems to respond to the predicate $>$ argument orientation.
\end{abstract}

Key words: lexical combinatory relationships, selection restrictions, collocations, lexicographic boundaries, predicates and arguments.

Recibido: 21/08/09.

Aceptado: 02/ 11/09. 


\section{INTRODUCCIÓN}

La selección lingüística, como sabemos, es de naturaleza categorial y semántica a la vez ${ }^{1}$. Por ejemplo, todo verbo transitivo selecciona habitualmente sintagmas nominales como argumentos, los cuales se realizan como s u j e to (el argumento externo) y como c o m p le m e n t o s (los argumentos internos); así en comer, verbo de dos argumentos, el último de los cuales se proyecta como objeto directo. Lo mismo ocurre con los adjetivos, que, por definición, seleccionan como primer argumento un sustantivo (i.e tacaño, en "hombre tacaño") y, en ocasiones, también un objeto preposicional (como oriundo en "persona oriunda de Santiago"). Sin embargo, para que las unidades léxicas puedan usarse con propiedad deben satisfacer, además, requisitos de naturaleza semántica, tal como se aprecia en estos mismos ejemplos. Los dos argumentos que selecciona comer aparecen semánticamente subcategorizados con los rasgos de '+animado' (el primero) y de ' \pm animado <comestible>' (el segundo); los casos en que esto no es así, deben entenderse como usos figurados o privativos de una jerga ${ }^{2}$. Por su parte, el adjetivo tacaño, del segundo ejemplo, no solo selecciona un sustantivo como su argumento: también le exige a este que pertenezca a la categoría de 'persona', contrariamente a oriundo, que puede predicarse de una 'persona' (como en el tercer ejemplo) tanto como de una 'cosa' (i.e. Son telas oriundas de la India), y cuyo último argumento requiere siempre la mención de un 'lugar de procedencia', introducido por la preposición de, regida sintácticamente por este adjetivo.

Rasgos "categoriales", de "subcategorización" y de "selección" como los aquí señalados, forman parte de la descripción sintáctica de las unidades léxicas en la gramática de la Teoría Estándar de Chomsky (1965). El verbo comer quedaría recogido aquí, de acuerdo con estos parámetros, de la siguiente manera:

comer $[+\mathrm{V}] ;+\left[{ }_{-} \mathrm{SN}\right]_{\mathrm{sv}} ;[+ \text { animado }]_{\mathrm{sN}} ;_{-}[ \pm \text {animado }<\text { comestible }>]_{\mathrm{sN}}$

\footnotetext{
1 La distinción "selección-C(ategorial)" y "selección-S(emántica)" se formula por primera vez en Chomsky (1986).

2 Esta entrada de comer corresponde a la de un uso recto del verbo; en su uso figurado, este puede presentar otras restricciones de selección (como en La polilla se comió la tela de la cortina o en El óxido se comió el metal).
} 
En la Teoría Estándar, sin embargo, las propiedades de selección forman parte de los rasgos sintácticos del Lexicón (cf. Chomsky 1965). Son, además, de naturaleza fundamentalmente extralingüística y, en consecuencia, tienen escaso valor en la descripción gramatical de las entradas léxicas. Es por esta razón que, en la Teoría de Rección y Ligamiento, la información relativa a los rasgos generales de selección (etiquetados como 'humano', 'animado', 'objeto material', 'comestible', 'artefacto', 'instrumento', etc.), aparece complementada con otra, correspondiente a la estructura temática de las piezas léxicas, según se muestra a continuación en esta otra entrada verbal (en Mendikoetxea 2004: 15):

poner V, \{Agente, Tema, Meta\} [ _ SN ‘objeto’; SP ‘ubicación'].

En muchos casos, la bibliografía nos ofrece descripciones del léxico que atienden exclusivamente a la propiedad de selección temática de los predicados:

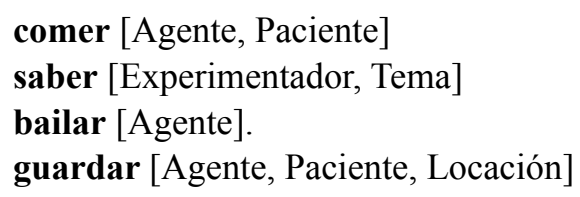

Sin subestimar la importancia de esta información para el conocimiento de la estructura del léxico, hay que decir que tampoco estas "restricciones" dan cuenta de toda la complejidad o la riqueza del proceso de selección en un sistema lingüístico. Y es que ciertas unidades léxicas imponen restricciones semánticas más fuertes a sus argumentos; vale decir, no basta con que estos pertenezcan a una clase o categoría de seres, ni que puedan desempeñar una u otra función semántica (Agente, Paciente, Experimentante, Meta, etc.) en la oración. El verbo abdicar, v. gr., junto con seleccionar un sujeto de persona, requiere que este designe a un individuo que ejerza ciertas funciones propias de un 'soberano'; el verbo, además, exige complementos del tipo trono, corona o cetro, de manera que no podría predicarse, por ejemplo, de un ministro de Estado, de un académico, de un profesor o de un cocinero (todos con el mismo valor temático de Agente o Causante). Del mismo modo, el adjetivo marimacho se predica de 'mujeres' con determinadas características físicas y el adjetivo mujeriego solo se aplica a 'hombres' con ciertos rasgos de personalidad.

Es en este contexto donde cobra valor el diccionario REDES, cuyo concepto de "clase léxica", en que se funda, es primordial para dar un paso adelante en la comprensión de las selecciones restrictivas que operan en las 
lenguas naturales. En relación con esto, léanse las siguientes reflexiones del autor a propósito del verbo derrumbarse:

También aquí es posible construir dos paradigmas. El primero (rascacielos, casa, pared, muralla, castillo, cielo...) se puede deducir casi automáticamente de una buena definición del diccionario. De nuevo, construir el paradigma físico no es especialmente difícil [...]. Pero, como sabemos, en español [...] se derrumban los sueños, las esperanzas, las expectativas, los planes, las ilusiones y otras nociones similares a estas [sic]. De nuevo, se trata de una lista limitada y bastante restringida: las dudas, por ejemplo, no se suelen derrumbar, sino más bien disipar, dispersar o desvanecer, por lo que se colocan -en español- más cerca de las nubes que de los rascacielos.

Esta información no aparece en los diccionarios, pero es objetiva y, como señalo arriba, debe ser aprendida específicamente por el que estudia español. Si un hispanohablante intenta reproducir en inglés, en alemán o en ruso los usos figurados de acariciar (acariciar el éxito, un proyecto, etc.) es posible que tenga algunos problemas que no se le plantearán si se limita al uso estrictamente físico (acariciar un gato).

(Bosque 2004: CI-CII).

Concretamente, lo que el autor defiende es que las listas de palabras proporcionadas en los artículos analíticos de REDES (los argumentos de los predicados-lemas, como sabemos) no se obtienen necesariamente del conocimiento de la realidad, sino del análisis del idioma (Bosque 2004: C). Son, por consiguiente, resultado de combinaciones esencialmente lingüísticas.

De selecciones semánticas restrictivas queremos hablar en este trabajo. El objetivo será determinar cuántas formas de selección es posible establecer a partir de las restricciones (tanto léxicas como semánticas) que se observan en los contornos de las definiciones lexicográficas de los diccionarios generales de lengua. Este examen nos permitirá afirmar que en las llamadas colocaciones -en su sentido más amplio y general- el proceso de selección lingüística se cumple del mismo modo que en otras formas de relación sintagmática. Sostendremos, consiguientemente, que la cuestionada "direccionalidad" de la selección léxica no parece ser tal, en la medida en que es posible reducirla en todos los casos a la consabida relación predicado-argumento.

Empezaremos por mostrar cómo se concibe la noción de "direccionalidad" en dos de los diccionarios onomasiológicos más importantes de la lexicografía española actual, DICE y REDES. Posteriormente observaremos qué tipo de restricciones se encuentran señaladas en los contornos de las definiciones de los diccionarios semasiológicos de español del último decenio. Como es 
natural, nos detendremos solo en las definiciones donde los contornos estén "expresados", con o sin delimitación formal, centrándonos particularmente en verbos y adjetivos, que son las categorías de palabras a las cuales dichos diccionarios aplican el método de modo preponderante.

\section{EN LOS DICCIONARIOS MONOLINGÜES ONOMASIOLÓGICOS DE ESPAÑOL}

Contrariamente a los diccionarios semasiológicos, cuyos artículos se estructuran en función de la definición de sus voces de entrada, los onomasiológicos están ideados para proporcionarnos palabras, 'formas' de decir o denominar determinados conceptos.

En español, son dos los diccionarios onomasiológicos que se construyen de acuerdo con la noción de argumento: DICE (proyecto en proceso) y REDES (2004); en consecuencia, ambos nos informan del contorno ${ }^{3}$ de las unidades léxicas que aparecen incorporadas en sus respectivas nomenclaturas, aunque de manera distinta.

\subsection{El Diccionario de colocaciones de español (DICE)}

En el DICE, los artículos lexicográficos comprenden tres zonas bien diferenciadas (siguiendo el modelo del DEC) ${ }^{4}$ : zona semántica, zona sintáctica y zona léxico-semántica.

Por ejemplo, en la z o n a s e má n ti c a de la palabra pena, se ingresan 3 acepciones ${ }^{5}$, cada una de las cuales se presenta con una suerte

3 Para la noción de contorno lexicográfico, véase, entre otros: Ahumada 1987, Teso 1997, Gutiérrez 1994, Alvar 1995, Abad 1997, Porto-Dapena 1980, 1988, 2002, Bajo 2000, Medina 2003, Serra 2006.

4 Descripciones del DICE se encuentran en Alonso Ramos (1989) y Sanromán (2003). También disponible en línea web.

5 En el DICE, no existen lemas polisémicos. Si una palabra tiene más de una acepción, como es el caso de pena, cada una se ingresa como una unidad léxica distinta y se le dedica un artículo lexicográfico completo. 
de "etiqueta semántica", que expresa su significado central, básico. Si bien permite identificar y diferenciar sentidos, la etiqueta en cuestión no constituye exactamente una definición: pena 1 'sentimiento' (como en tener alguien pena); pena 2 'hecho' ( como en pasar alguien penas); pena 3 'acción' (como en imponer uno penas a otro).

Inmediatamente después de la etiqueta semántica, el DICE describe, mediante una glosa, la "forma proposicional" que corresponde al significado de la entrada. En esta fórmula se recoge precisamente la red de argumentos constitutiva de cada unidad léxica. A la glosa sigue un ejemplo de uso, con ayuda del cual el lector puede comprobar la configuración actancial en cada caso descrita:

\section{pena 1 'sentimiento'}

Glosa: pena de individuo X por hecho Y.

Ejemplo: No tengáis pena, de verdad, que estoy estupendamente.

pena 2 'hecho'

Glosa: penas de individuo $\mathrm{X}$ provocadas por hecho $\mathrm{Y}$.

Ejemplo: Con muchas penas y fatigas llegamos a la cumbre. Todos hemos pasado nuestras penas. Las penas de la posguerra.

pena 3 'acción'

Glosa: pena de organismo social o individuo $\mathrm{X}$ a individuo $\mathrm{Y}$ por haber hecho $\mathrm{Z}$ y consistente en $\mathrm{W}$.

Ejemplo: Le impusieron una pena de diez años.

En la z o n a s in tá c t i c a de los artículos del DICE se indican las diferentes estructuras que en español puede adoptar la "realización" de los argumentos explicitados en la zona anterior. Así, en el caso de pena 1 tenemos, por ejemplo: a) la pena del niño $<$ su pena $>$; b) la pena por $<$ a causa de > la pérdida de su madre; c) pena de perder a su madre; d) pena por haber perdido a su madre.

En la z o n a lé x i c o-s e má n t i c a, por último, se listan todas las palabras que forman colocación con la unidad que encabeza el artículo (vale decir, el lema). En este modelo, como se sabe, las colocaciones se explican por medio del dispositivo de las "funciones léxicas" (FFLL), ideado por Mel'cuk y aplicado sistemáticamente en las sucesivas publicaciones del DEC. Dicho en términos sencillos, una función léxica (FL) es un "sentido

\footnotetext{
6 Estas etiquetas semánticas están inspiradas en el DICO (Diccionario de Colocaciones del francés). Ver Polguère 2000.
} 
o un papel semántico-sintáctico tal que su expresión depende del lexema al que esta FL se aplica" (Alonso 1994-95: 22). Tomemos ahora como ejemplo el sustantivo alegría, y pensemos en algunos de los adjetivos de que dispone el español para expresar la idea de que esta (la alegría) es grande, intensa o que se manifiesta en alto grado (en el modelo de la Teoría Sentido-Texto, se representa mediante la notación MAGN). Seguramente pensaremos en palabras como desbordante, indescriptible, inmensa, loca, etc. Pues bien, todas ellas (o cada una por separado) constituyen el 'valor' de la FL. La palabra a la que se aplica esta función es llamada 'palabra llave' o 'palabra base'. La misma FL aplicada a otras palabras da como resultado nuevas colocaciones. He aquí algunos ejemplos; la palabra llave aparece entre paréntesis:

Magn $($ cariño $)=$ entrañable, sincero

Magn (error) $=$ craso

Magn (beneficios, ganancias) $=$ pingüe

Magn $($ comida $)=$ opíparo

Magn (odio) $=$ mortal

Magn (ira) $=$ ciega

Magn $($ ignorancia $)=$ supino

Como se ve, aquí las bases corresponden todas a sustantivos; pero pueden pertenecer también a la categoría de verbo:

Magn $($ negar $)=$ rotundamente

Magn (creer) $=$ a pie juntillas

Magn $($ odiar $)=$ a muerte

Magn $($ confesar $)=$ abiertamente

Magn $($ rehusar $)=$ firmemente

Veamos cómo se ingresa información como esta en los artículos del DICE. Volveremos sobre las colocaciones formadas a partir de alegría a la que aplicaremos la FL Magn (la más productiva del modelo):

ALEGRÍA+ADJETIVO

Volver $>>$

INTENSA FL $M A G N$

a raudales Alegría a_raudales, que diría un cursi 


\section{INTENSA FL $M A G N$}

enorme hubo música, canciones, fuegos artificiales, rayos láser y globos en un ambiente informal y de enorme alegría.

\section{INTENSA FL $M A G N$}

gran Hay momentos que siento una gran alegría y otras en los que me encuentro muy deprimido.

\section{INTENSA FL $M A G N$}

impagable esa alegría impagable de saberse leído, comprendido y admirado en más amplios círculos.

\section{INTENSA FL $M A G N$}

inefable celebraba con inefable alegría la solemnidad del nacimiento del niño Jesús (web).

INTENSA FL $M A G N$

inmensa Saldré a darlo todo. Mi alegría es inmensa; Llegar a Milán ha sido para muchos un sueño no cumplido, para los supervivientes ha supuesto la inmensa alegría de culminar el Giro más duro, y a_la_vez emocionante, de los últimos años.

INTENSA FL $M A G N$

intensa Una posición realista afirma, por el contrario, que en todo caso el arte es la más intensa alegría que el hombre se proporciona a sí mismo; Pero, aunque todo parecía transcurrir dentro de la más sana e intensa alegría, no iba a tardar en estallar el «escándalo»...

INTENSA FL $M A G N$

tremenda débilmente, empezó a moverse, lo que nos causó una alegría tremenda.

Repárese en que a cada colocación se le asigna un artículo, en el que se indica la FL, el valor de dicha función (que, con una sola excepción, corresponde al adjetivo que se proporciona en cada artículo) y uno o más ejemplos que la ilustran ${ }^{7}$.

7 Otras FFLL pueden ser aplicadas a la palabra llave alegría, por ejemplo, la de VER (atributo que significa 'tal como debe ser', 'correcto') y la de Anti-Ver (atributo de significado 
En la Teoría Sentido-Texto ${ }^{8}$, que es el marco teórico en que se sustenta el diccionario de colocaciones que comentamos, es la palabra base (siempre un sustantivo o un verbo) la que selecciona sus colocativos (que, a su vez, son normalmente predicados). En el DICE (así como en el DEC), se parte del supuesto de que el usuario ingenuo de su lengua o un aprendiz de ella puede conocer las bases pero ignorar los colocativos con los que podrían combinarse para formar colocaciones. Esta idea, unida a la condición de "seleccionadoras" que se les atribuye a las bases, hace que en estos diccionarios sean estas las que se ingresen como lemas o cabezas de artículos. Algo muy distinto ocurre en REDES, el otro diccionario combinatorio de español, como más abajo veremos.

\subsection{REDES, DICCIONARIO COMBINATORIO DEL ESPAÑOL CONTEMPORÁNEO}

En REDES, en contraposición con el DICE, los lemas son únicamente piezas léxicas predicativas (no solo sustantivos y verbos; también adjetivos, adverbios y algunas preposiciones), por lo que el cuerpo del artículo está formado por los argumentos que estas seleccionan, en consonancia con las teorías gramaticales de base léxica imperantes en la actualidad. En REDES, la unidad básica de análisis no la constituye, en verdad, la colocación ${ }^{9}$, pero la relación que allí se establece entre los predicados y sus argumentos corresponde a la que Alonso $(1994-95,2002)$ describe como bases y colocativos $^{10}$, inversamente.

Así, entonces, ante una colocación como "prohibir terminantemente", la autora del DICE dirá que el verbo es la base y el adverbio el colocativo. La selección de terminantemente por el verbo prohibir estaría determinada por la función léxica Magn, que ya hemos mencionado. Bosque (2001a,

opuesto al anterior). A partir de estas funciones se pueden originar colocaciones como las siguientes:

VER $($ alegría $)=$ verdadera, franca, sincera, etc.

ANTI-VER (alegría) $=$ falsa, fingida, forzada, etc.

8 Esta teoría aparece esbozada por primera vez en un artículo publicado por Zholkovsky y Mel'cuk en 1965, donde proponen un método para la síntesis semántica de textos; o dicho de otro modo, para la generación de textos a partir de sentidos. Véase Apresjan 1992 y Mel'cuk 1989, 1992, 1997 para una introducción a la teoría (Sanromán 2003).

9 Bosque $(2001,2004,2006)$ entiende que, como término técnico de la lingüística, es todavía demasiado ambiguo.

10 Fernando López Martínez (2004), explicando cómo se delimitan los argumentos en REDES, se refiere a estos como bases, y a los predicados como colocativos. 
2001b, 2004, 2005), en cambio, dirá que es el adverbio el que selecciona al verbo, y no al revés. Más aún, dirá que terminantemente, en su calidad de predicado, no selecciona solamente prohibir y otros verbos con significado próximo a este, sino que selecciona c l a s e s lé x i c a s, cada una de las cuales está formada por un número dado de expresiones (los argumentos), agrupadas a partir de ciertos "rasgos semánticos" comunes, que son los que permiten formar la clase, justamente. Así, prohibir forma parte de la clase de "verbos que designan acciones coercitivas o autoritarias, en particular, diversas formas de fijar, imponer o impedir algo", junto con obligar, ordenar, establecer, disponer, etc. Otras clases son, por ejemplo, la de los "verbos que denotan oposición o rechazo en diversos grados", a la que pertenecen oponerse, rechazar, rehusar, excluir, etc., o la de los "que denotan exposición, declaración o sostenimiento de una postura o un punto de vista", que agrupa predicados como manifestar, declarar, afirmar, sostener, pronunciar, etc. Para cada argumento, REDES ofrece ejemplos de uso obtenidos de fuentes mayoritariamente periodísticas.

De esta manera, REDES pone en evidencia que la combinación de prohibir con terminantemente no es una relación exclusiva entre lexemas, así como tampoco lo es la que se establece entre los miembros de craso error, pingües beneficios, ignorancia supina, rehusar firmemente y tantas otras que han sido tratadas como colocaciones en lexicografía española.

La noción de "restricción léxica", introducida por Bosque en la lexicografía hispánica (Muñiz 2005: 177), presupone una relación entre la in te n sión (o significado) de un predicado y su exte n s i ón (o ámbito de aplicación). Mientras las clases léxicas se formulan mediante trazos "intensionales", por así decir (los rasgos semánticos que dan lugar a la clase), las listas que así se obtienen corresponden a la información "extensional" de los predicados.

Mostraremos, a continuación, cómo están diseñados los artículos lexicográficos en este diccionario. En primer lugar, hay que señalar que REDES utiliza dos tipos de artículos, en los que se exponen datos de índole diversa. En uno de ellos, el "analítico", el más importante y el verdaderamente innovador en esta obra, el lema está seguido por una 'marca gramatical', en cursiva (como en los diccionarios de lengua tradicionales); por una 'entradilla', donde se proporciona información combinatoria de índole general, y, cuando la voz en cuestión es polisémica, por una descripción somera del o los sentidos que se le atribuyen. Luego se listan las palabras que se comportan como sus argumentos. Cuando estos forman un grupo semánticamente diverso, REDES los ordena en clases léxicas, como ya se dijo, que se identifican mediante letras mayúsculas y que se disponen verticalmente; de lo contrario, simplemente se mencionan (véase frugal, 
módico y perpetrar). Al final del artículo, así como en otros diccionarios, se hallan las 'remisiones', que aquí están precedidas del signo $\square$, y que ofrecen al lector una o más palabras semánticamente afines o próximas a la de la entrada (REDES 2004: LI, LII).

frugal $a d j$. almuerzo, aperitivo, cena, colación, consumición, desayuno, merienda; otros sustantivos que designan comida.

módico adj. cantidad, cifra, descuento, ingreso, pago, precio

perpetrar $v$. asalto, asesinato, crimen, delito, homicidio, robo.

El siguiente es un ejemplo de artículo en el que el predicado de la entrada selecciona un alto número de argumentos, por lo que, aparte de enumerarlos, se hace necesario ordenarlos por c l a s e s . Los argumentos de uso más frecuente ocupan los primeros lugares de la lista, normalmente precedidos de marcas de frecuencia ${ }^{11}$. Omitiremos en esta oportunidad los ejemplos con que se ilustran los distintos argumentos seleccionados por el predicado:

abrupto adj - En el sentido de 'escarpado, de difícil acceso o con una gran pendiente' se combina con sustantivos que designan lugares o territorios (terreno, región), así como con otros que expresan accidentes del terreno (relieve, acantilado, barranco) o vías (carretera, camino, senda). En el sentido de 'áspero, violento, rudo, destemplado' se combina con sustantivos de persona, y también con muchos de los que expresan cambios de estado. Destacan sus combinaciones con:

A Sustantivos que denotan interRupCión o Final de algo. TambiÉn CON OTROS QUE DESIGNAN LAS ACCIONES QUE PROVOCAN EL CESE O EL TÉRMINO $D E A L G U ́ N$ ESTADO DE COSAS: $\mathbf{1}$ final ++ $\mathbf{2}$ corte ++ $\mathbf{3}$ cese $\mathbf{4}$ cierre $\mathbf{5}$ fin $\mathbf{6}$ interrupción +7 cancelación 8 renuncia 9 eliminación 10 dimisión 11 expulsión 12 ruptura 13 marcha 14 encabalgamiento 15 aterrizaje 16 despedida 17 retiro 18 suspensión 19 separación.

11 Los diacríticos utilizados en REDES son:

++ combinación sumamente frecuente;

+ combinación bastante frecuente;

-- combinación poco frecuente en los textos, aunque posible y casi siempre atestiguada.

La ausencia de cualquiera de estos signos significa que, pese a no ser frecuente, la combinación está atestiguada y que suele resultar aceptable a los oídos de un hablante nativo (REDES 2004: XLVII). 
B Sustantivos QUE DENOTAN INICIO, INGRESO, INTRODUCCIÓN O SURGIMIENTO $D E A L G O: \mathbf{2 0}$ principio $+\mathbf{2 1}$ presentación $\mathbf{2 2}$ obertura $\mathbf{2 3}$ irrupción + 24 explosión 25 salida 26 descubrimiento 27 brote 28 arranque 29 despertar.

C Sustantivos que denotan aumento o incremento: 30 crecimiento + 31 aumento 32 subida 33 crecida 34 incremento 35 alza 36 suba 37 repunte $\mathbf{3 8}$ enriquecimiento.

D Sustantivos gue DENOTAN DisminuCión O PÉRDIDA DE ALGUNA MAGNITUD: 39 caída ++40 descenso 41 bajada 42 disminución 43 reducción 44 recesión 45 pérdida 46 devaluación 47 desaceleración 48 depreciación 49 contracción 50 baja 51 ajuste.

E OtROS SUSTANTIVOS QUE DENOTAN TRANSFORMACIÓN O MODIFICACIÓN: 52 cambio ++ 53 alteración 54 modificación 55 transformación 56 sustitución 57 transición 58 traslado 59 giro 60 vaivén 61 fluctuación.

F Sustantivos que designan obras de CREación, así COMO algunas de SUS PARTES, SUS CARACTERÍSTICAS DESTACADAS O LOS GÉNEROS A LOS QUE PERTENECEN: 62 libro 63 relato 64 prosa 65 párrafo 66 monólogo 67 tragedia 68 partitura 69 rock 70 balada 71 obra.

G Diversos sustantivos gue expresan acciones VERbales. También CON OTROS QUE DESIGNAN UNIDADES DE INFORMACIÓN Y ACCIONES QUE SE SUELEN REALIZAR VERBALMENTE: $\mathbf{7 2}$ advertencia $\mathbf{7 3}$ debate $\mathbf{7 4}$ declaración $\mathbf{7 5}$ descalificación 76 discurso 77 exordio 78 jerga 79 lengua 80 respuesta 81 titular.

H Sustantivos QUE DESIGNAN PROPIEDADES, EN PARTICULAR, CIERTAS FORMAS DE SER O DE ACTUAR: $\mathbf{8 2}$ carácter $\mathbf{8 3}$ estilo $\mathbf{8 4}$ belleza $\mathbf{8 5}$ seguridad $\mathbf{8 6}$ franqueza.

I Algunos sustantivos de MoVimiento. TAMbiÉN CON OtRos QUE DESIGNAN ACCIONES QUE SE ASOCIAN CON UN LÍMITE NATURAL O CON EL ENCUENTRO DE ALGÚN OBSTÁCULO: $\mathbf{8 7}$ movimiento $\mathbf{8 8}$ oclusión $\mathbf{8 9}$ choque.

En este, como en otros casos de artículos analíticos, queda de manifiesto que, en la lengua, operan dos códigos distintos, un código literal o primitivo (p), y otro derivado o figurado (f) ${ }^{12}$, cada uno con un comportamiento gramatical diferente (que se expresa justamente en la distinta red de argumentos que en cada caso se selecciona). Una de las motivaciones de Bosque para la confección de REDES ha sido, precisamente, la convicción de que, en los diccionarios convencionales, la forma en que están definidas las palabras no permite hacer deducciones de cómo deben combinarse (Bosque 
1982, 2001a, 2001b, 2004). Es de notar, además, que las clases léxicas, tal como se formulan en REDES, inducen a interpretar los usos figurados como extensiones naturales de los usos físicos.

El otro tipo de artículo en REDES es el "abreviado". Aquí, la información se expone de modo semejante a como suele hacerse en un diccionario combinatorio convencional; vale decir, consta únicamente de un listado de palabras relacionadas de algún modo con la entrada ${ }^{13}$. Veamos el ejemplo de sueño. El signo - se utiliza para indicar las acepciones en relación con las cuales se organizan los listados (acepciones expresadas sumariamente entre paréntesis); el signo separa los argumentos por categorías léxicas. Los números en superíndices con que muchas de las palabras aparecen marcadas remiten al lector a los artículos analíticos, donde tales palabras están ingresadas como predicados. De esta manera, la referencia borroso ${ }^{11}$, por ejemplo, significa que en la entrada correspondiente a borroso, el sustantivo sueño aparece en el número 11. Es así como todas las palabras del diccionario se hallan interconectadas, formando redes, y la información puede recuperarse desde diversos puntos del repertorio léxico.

sueño - (aspiración) ambicioso, antiguo, borroso ${ }^{11}$, contagioso $^{16}$, de grandeza, de los justos, de oro, descabellado ${ }^{12}$, dorado, efimero ${ }^{24}$, eterno, febril ${ }^{45}$, fugaz, ideal, ilusionado, inalcanzable ${ }^{2}$, irrealizable, irrenunciable ${ }^{11}$, largo, loco, máximo, mayor, pasajero, utópico, vano ${ }^{17}$, viejo $\bullet$ abandonar(se) (a), abrigar ${ }^{9}$, acariciar $^{11}$, acometer, alcanzar, alimentar ${ }^{8}, \operatorname{alimentar}(\mathrm{se})$ $(\mathrm{de})^{5}$, ansiar, apoderar(se $)^{27}$, colmar $^{3}$, combatir $^{15}$, conservar ${ }^{44}$, converger, cristalizar, culminar ${ }^{16}$, cumplir $^{8}$, defraudar ${ }^{8}$, derribar, derrumbar(se $)^{51}$, desbaratar ${ }^{30}$, desmoronar(se $)^{16}$, destruir, desvanecerse ${ }^{1}$, difuminar(se $)^{25}$, dispersarse $^{16}$, echar ${ }^{53}$, encarnar, forjar ${ }^{27}$, frustrar(se), hacer(se) realidad ${ }^{1}$, impulsar, llevar a buen puerto ${ }^{24}$, llevar a la práctica ${ }^{11}$, lograr, madurar $^{30}$, mantener (vivo), perder, persistir (en $)^{34}$, pisar $^{7}$, pisotear $^{18}$, poner fin (a), realizar(se), sumir(se) $(\mathrm{en})^{34}$, tejer ${ }^{35}$, tener, truncar(se) $)^{7}$, venirse abajo ${ }^{2}$.

- (deseo de dormir) apacible, feliz, ligero, pesado plácido, prolongado, profundo, reconfortante, reparador fase (de), cara (de) caerse (de), coger, combatir, conciliar, despertar (de), dominar, dormir, entrar (a alguien), entregar(se) (a), hablar (en), perder, perturbar, quitar (a alguien),

\footnotetext{
${ }^{13}$ Nos referimos, entre otros, a los siguientes diccionarios: BBI combinatory of English word combinations (1986, 1997); Collins Cobuild English Collocations (1995); Dictionnaire de cooccurrences de Beauchesne (2001); LTP Dictionary of Selected Collocations, de Hill y Lewis (1997); Euléxico de Boneu (2000); Oxford Collocations Dictionary for Students of English (2002).
} 
resistir(se) (a), robar(le) (a alguien), tener, trastornar, velar, vencer, vigilar.

- (ensoñación) $\downarrow$ recurrente olvidar, recordar, repetir (se), tener.

$\checkmark$ Véase también aspiración, deseo, ilusión, imaginación, modorra, pesadilla, utopía.

Dado que el lema es un sustantivo, las unidades listadas corresponden a los adjetivos y a los verbos con los que aparece combinado en otros artículos del diccionario. Esto quiere decir que sueño es también una palabra seleccionada como argumento por otras. En relación con los verbos, el sustantivo puede funcionar como sujeto (como en desvanecerse un sueño), o bien como objeto directo (como en alcanzar (alguien) un sueño) u objeto preposicional (como en hablar en sueños).

Es especialmente significativo destacar que la información que se entrega en este tipo de artículos no se elabora expresamente, sino que es el resultado de la aplicación de un sistema informatizado de búsquedas; dicho de otro modo, lo que en otros diccionarios combinatorios constituye un fin en sí mismo (aportar listas de palabras) $)^{14}$, "surge" aquí automáticamente del ordenador, al que se le han entregado antes los datos verdaderamente relevantes. Los artículos sintéticos son posibles, entonces, gracias a los analíticos, donde los datos del corpus disponible han sido previamente estudiados y ordenados.

\subsection{CONSIDERACIONES CRÍTICAS}

DICE y REDES, aunque distintos en sus planteamientos y objetivos, son diccionarios que se complementan. En primer lugar, no solo son diccionarios combinatorios del español sino que, además, explican las combinaciones léxicas a partir de relaciones semánticas; el primero lo hace desde la perspectiva de las "funciones léxicas" de Mel'cuk y el segundo desde la

14 Los artículos lexicográficos de Euléxico son todos de la misma factura del que ahora citamos:

FENÓMENO. Verbo > acaecer un, constituir un, consumar(se) un, presenciar un; plural) obrar

Adjetivo > aislado, apoteósico, asombroso, caprichoso, desacostumbrado, desusado, esporádico, excepcional, extraordinario, fantástico, inaudito, indescriptible, inédito, inenarrable, insólito, inusitado, inverosímil, irreproducible, ocasional, pasmoso, portentoso, prodigioso, simpar, singular, soberbio, sobrehumano, sobrenatural, sorprendente, supremo. 
noción de "restricción léxica" de Bosque. Siendo distintos los puntos de partida, son también distintos los resultados. Las palabras que nos aporta el DICE son semánticamente predicados (y operan, por tanto, sobre las bases, que a su vez son las voces de entrada); las palabras que nos aporta REDES, en cambio, son semánticamente argumentos (vale decir, unidades léxicas seleccionadas por otras que se ingresan al diccionario como lemas). DICE y REDES, en consecuencia, difieren en la orientación de la s e le c c i ó n lé x i c a : de la base al colocativo, por un lado; del colocativo a la base, por otro.

La relación léxica orientada desde la base al colocativo es la concepción más unánimemente aceptada en la lexicografía actual ${ }^{15}$. Sin embargo, nótese que el orden que en ella se establece parece contradecir el orden en que se producen las relaciones en la sintaxis de una lengua; en efecto, en combinaciones como las de cariño entrañable, ira ciega, pingües beneficios, etc., los colocativos (los adjetivos entrañable, ciega, pingües) son, por definición, p r e d i c a d o s, y consiguientemente, las bases a las que se adjuntan (los sustantivos cariño, ira, beneficios) son a r g u m e n t o s suyos. Las mismas observaciones son válidas para los casos en que la base es un verbo: en influir poderosamente, prohibir terminantemente, negar a pie juntillas ofluir caudalosamente, los verbos influir, prohibir, negar y fluir, si bien son predicados, no exigen, y por tanto en rigor no seleccionan, las unidades con las que aparecen combinados en estos sintagmas.

Por esta razón estimamos que la orientación inversa, la que parte del predicado, es mucho más explicativa para una teoría lingüística, toda vez que permite dar cuenta de $\mathrm{t}$ o $\mathrm{d}$ a s las combinaciones de predicado $>$ argumento del lexicón. De manera tal que las "colocaciones", si es que realmente existen como fenómeno particular en las lenguas, no describirían sino un tipo especial de combinación, como de hecho pensamos que ocurre.

Cabe preguntarse, por otra parte, si lo que debe entenderse como colocación, en una entrada como la de alegría del DICE, involucra únicamente d o s unidades léxicas, esto es: la palabra objeto de estudio más la unidad con la que en cada caso forma sintagma (que habría que entender como implicada en cada artículo: alegría + desbordante, alegría + inmensa, alegría + indecible, alegría + impagable, etc.), o bien es la relación que se establece entre alegría y todas las formas con las que puede combinarse, lo cual permitiría afirmar que el sustantivo alegría "se coloca"

15 Fuera del DEC y del DICE, son diccionarios combinatorios de orientación argumento $>$ predicado los siguientes: BBI, CCEC, LTP, OCD, LAF (en preparación). 
en español con los adjetivos desbordante, inmensa, indecible, impagable, loca, etc. La forma en que DICE confecciona sus artículos parece invitarnos a interpretar como colocaciones nada más que las combinaciones del primer tipo, entendidas como una relación "uno a uno"; pero es harto decidor el hecho de que la misma unidad admita, no una, sino múltiples combinaciones en lengua española.

Creemos, por lo expuesto, que el concepto de selección que maneja Bosque es más apropiado que el de su contraparte para dar cuenta de las restricciones a que se ven sometidas las unidades léxicas predicativas en el uso lingüístico, las que se definen precisamente por su capacidad de seleccionar unos determinados argumentos. Para muchos de los casos en que la bibliografía ofrece una relación "binaria" entre lexemas, Bosque comprueba, a través de REDES, que tal relación es cuestionable y que, por lo tanto, merece replantearse. Así, por ejemplo, el adjetivo supino no solo admite combinación en español con ignorancia, sino también con desconocimiento, error, estupidez, incompetencia, inutilidad, necedad, sandez, ingenuidad y otros sustantivos que denotan carencia de conocimientos, de inteligencia o de perspicacia. Estos sustantivos forman la primera clase léxica que establece Bosque para explicar las relaciones combinatorias del predicado supino con los argumentos que selecciona; otras clases permiten entender por qué supino se usa (o puede usarse) también con sustantivos tales como arrogancia, hipocresía, irresponsabilidad, cinismo, pedantería, egoísmo, etc., que en conjunto designan "diversos rasgos negativos del comportamiento humano", en especial "si se relacionan con la ausencia de sinceridad, generosidad, honestidad o sencillez". De igual modo, no solamente decimos de los beneficios que son pingües, porque este adjetivo se predica de cualquier sustantivo que designe "beneficios" o alguna forma de "retribución", a la vez que las actividades económicas que se realicen con el propósito de conseguir esos resultados; por ello nos parece aceptable el uso de pingües con ganancias, sumas, recompensas, honorarios, intereses, dividendos, etc.

$Y$ es que al formular sus clases léxicas, Bosque no hace otra cosa que 'explicitar' las relaciones semánticas que existen entre ciertos lexemas; es como si cada clase léxica representara un "archisemema" que en español careciera de su correspondiente "archilexema". Cierto es que, en muchos casos, uno de los lexemas (o argumentos) de la clase hace las veces de archilexema (o hiperónimo) suyo, por ejemplo, delito en relación con perpetrar, razón por la cual resultan corrientes, además de perpetrar delitos, sintagmas donde aparecen los lexemas robo, asalto, crimen, entre otros semánticamente afines (co-hipónimos de delito). Tal vez la función de hiperónimos de muchos lexemas en relación con la clase de la que forman parte podría explicar la frecuencia con que aparecen en el discurso y, por 
tanto, la afirmación de que constituyen un "par léxico", vale decir, una colocación.

Entre los predicados verbales ingresados por REDES que se caracterizan por seleccionar un número significativo de argumentos, queremos citar estallar, una de las entradas (entre otras muchas) en que se advierte claramente la transición de los sentidos rectos a los figurados. Para este verbo se dice en REDES que, en su sentido de 'reventar o explotar' se combina con sustantivos que designan artefactos y sustancias (bomba, explosivo, dinamita), así como con nombres de diversos objetos materiales que pueden verse afectados por dichos eventos (edificio, coche, etc.). En su sentido de 'ocurrir de repente o de manera violenta', por otro lado, se combina con:

A Sustantivos que designan acciones que COnStituYen MANifEstaciones O EXPRESIONES DE DISCONFORMIDAD O REBELDÍA, GENERALMENTE DIRIGIDAS CONTRA UNA AUTORIDAD ESTABLECIDA: revolución, rebelión, protesta, revuelta, sublevación, disturbio, huelga.

B Sustantivos que designan situaciones, a MENudo violentas, de CONFRONTACIÓN U HOSTILIDAD ENTRE VARIAS PARTES: guerra, enfrentamiento, batalla, conflicto, combate, contencioso, litigio, lucha.

C Sustantivos que designan situaciones difíciles, adVERSAs, Disputadas O INCONVENIENTES: escándalo, crisis, polémica, controversia, alarma, problema.

D Sustantivos Que denotan enfrentamiento Verbal: discusión, disputa, bronca.

E Sustantivos que designan informaciones, a veces de Carácter púBLICO: rumor, noticia, habladuría.

F Sustantivos Que denotan evento o estado de cosas: tema, asunto, caso.

Vale destacar que este mismo verbo selecciona otros argumentos cuando rige determinadas preposiciones, como de ('estallar de') o en ('estallar en'):

estallar (de) $v \backsim$ Se combina con:

A Sustantivos que denotan sentimiento gozoso y, por extensión, su MANIFESTACIÓN O SU EXPRESIÓN: alegría, risa, júbilo, felicidad.

B Sustantivos Que DENOTAN IRRITACIÓN O DESIGNAN OtRos SENTIMIENTOS VIOLENTOS O EXALTADOS: ira, indignación, rabia.

estallar (en) $v$ 『 Se combina con:

A Sustantivos que designan la acción o el efecto de llorar: lágrima, llanto, sollozo. 
B Sustantivos que designan manifestaciones Ruidosas de las PersoNAS, QUE SE INTERPRETAN COMO SIGNOS DE ELOGIO O DE DESAPROBACIÓN: aplauso, ovación, vitores, silbido, clamor, vituperio, grito.

C Sustantivos Que Designan otras manifestaciones EXPANSIVAS DE UN SENTIMIENTO GOZOSO: carcajada, risa, jolgorio, alborozo.

D Sustantivos Que Designan irritación En Diversos GRAdos, así COMO ALGUNOS DE SUS EFECTOS: cólera, rabia, ira, indignación, violencia.

E Sustantivos Que denotan PolÉmicA o CONTROVERSIA ENTRE dos o mÁs PARTES: protesta, bronca, controversia.

En definitiva, lo que REDES viene a decirnos es que los predicados son capaces de seleccionar, no ya únicamente 'argumentos', sino unidades de mayor extensión semántica, como lo son las 'clases léxicas'. Y es justamente esto lo que hemos querido defender aquí, que los procesos lingüísticos de selección son variados, tal como mostraremos a continuación, sometiendo a examen los contornos de las definiciones lexicográficas de algunos diccionarios semasiológicos monolingües de español. La primera conclusión importante a que hemos llegado en este análisis es que los argumentos de los predicados no son, por definición, "huecos" o casillas vacías, ya que en muchos casos ellos son sintagmas únicos, como ocurre, por ejemplo, con ojo en relación con guiñar, o con huero en relación con huevo (cf. más adelante).

Puesto que entendemos el contorno como un método que explicita los argumentos de un predicado, y puesto que en muchos casos los contornos, en los diccionarios que consultamos ${ }^{16}$, comprenden colocaciones, en este trabajo nos serviremos fundamentalmente de los planteamientos de Ignacio Bosque para tratar el problema de las relaciones léxicas y su tratamiento en lexicografía.

16 Los diccionarios son DRAE, DEA, CLAVE, LEMA, DSAL, GDLE 1 (Sgel) y GDLE 2 (Larousse), DUE (2002). Ver siglario, al final. 


\section{EN LOS DICCIONARIOS MONOLINGÜES SEMASIOLÓGICOS DE ESPAÑOL}

Es posible establecer una clasificación de las restricciones semánticas de las piezas léxicas, de acuerdo con el menor o mayor grado de especificidad de los argumentos seleccionados por ellas. Según sabemos, los contenidos semánticos de los contornos de las definiciones aparecen más o menos 'acotados'. La información reunida nos ha permitido establecer c u a t r o grandes grupos, al respecto:

\section{PRIMERO:}

El primero corresponde a las definiciones en las que la restricción se formula de un modo muy general. En este caso, lo que el contorno encierra corresponde a una categoría, a un 'clasema' (en términos coserianos). La restricción es tan laxa, que puede expresarse mediante las formas pronominales algo, alguien, uno, otro, etc. Aquí podemos hablar de verdaderas "casillas vacías":

prestar 1 Dar [alguien algo a otro] con la idea de que se lo devuelva. apto -ta Que sirve [para algo] (DEA).

invitar 1 Pedir en acto de cortesía o de amistad [a alguien $(c d)$ ] que esté presente en un determinado acto o lugar ( $c o m p l$ A)] (DEA).

pedir 1 Rogar o demandar a uno que dé o haga [una cosa] (DALE).

hablar 3 Dicho de una persona: Comunicarse con otra u otras por medio de palabras (DRAE).

contener 1 Tener una cosa en sí misma o en su interior a $\rightarrow$ otra (DUE).

Se puede afirmar que únicamente uno y alguien poseen un valor semántico inequívoco, correspondiente a persona; otro / otra, puede referirse tanto a persona como a cosa (cp. hablar y contener). El elemento más ambiguo es, no obstante, algo. En lexicografía parece servir de 'comodín'. En el primero de los ejemplos anotados (prestar), se refiere a cosa; pero en el segundo (apto) alude también a 'evento' (alguien puede ser apto para cantar, para desempeñar una función, etc.).

En otras entradas, algo, por su carácter demasiado vago, debe acotarse, dentro del mismo contorno, mediante uno o más modificadores, lo que hace habitualmente DEA:

paliar 1 Mitigar o atenuar [algo negativo]. 
despertar 3 Producir [algo no material, esp un sentimiento o deseo], o hacer que se manifieste si estaba latente.

impartir 1 Dar [algo, esp espiritual] a muchos.

La restricción parece más definida cuando se formula con los genéricos persona, cosa, animal, lugar / sitio, etc.:

cursi 1. Dicho de una persona: Que presume de fina y elegante sin serlo. // 2. Dicho de una cosa: Que, con apariencia de elegancia o riqueza, es ridícula o de mal gusto.

sobrio -bria [Pers.] moderada, esp. en comer y beber (DEA).

agresivo, va 1. Dicho de una persona o de un animal: Que tiende a la violencia.

colorear 1 Dar < una persona > color a [una cosa] (DSAL).

enviar 1 Hacer que una $\rightarrow$ cosa llegue a cierto sitio o a alguien que está a cierta distancia (DUE).

También en este grupo nos encontramos con contornos en los que un argumento, ya incorporado en una categoría de seres (i.e. animal), recibe una segunda restricción que lo identifica como especie (i.e. puerco), como vemos en verriondo:

verriondo, -da [animal, esp. puerco] Que está en celo (DALE).

Según esto, un lector que desconociera el significado de esta palabra, no sabría si calificar de 'verriondo' a todos los animales en celo o exclusivamente a los puercos que se encuentran en tal situación. La misma observación vale para clueco-ca, adjetivo que al parecer aplicamos restrictivamente a gallina y no a aves en general, como aparece en DEA:

clueco -ca 1 [Ave hembra] que está en situación de empollar. Frec $n$ fesp referido a la gallina que empolla o que cuida los pollos recién nacidos.

Una restricción genérica limitada por otra, de especie, hallamos asimismo en trasquilar:

trasquilar 2 Referido a un animal, esp. a una oveja, cortarle el pelo o la lana (DUE).

Nuevamente, vale preguntarse si, cuando cortamos el pelo a nuestros gatos o perros domésticos, también los trasquilamos. Insistimos en la necesidad de precisar convenientemente las restricciones para que no 
induzcan a error. En estas otras entradas, se opta por indicar únicamente conceptos genéricos:

trasquilar 2 Cortar el pelo o la lana a algunos animales (DRAE).

trasquilar 1 Esquilar a un animal (DEA).

\section{SEGUNDO:}

El segundo grupo de restricciones semánticas está constituido por los predicados cuyos argumentos deben satisfacer "rasgos" semánticos más acotados, más definidos. El contorno suele expresarse, aquí, mediante un hiperónimo (un archilexema, en la teoría de las solidaridades léxicas de Coseriu). Consecuentemente, entre las unidades léxicas que pueden actualizar tales argumentos se encuentran hipónimos suyos, como los que vemos aparecer en los ejemplos con que, en los mismos diccionarios, se ilustran los conceptos o los usos de ciertos definidos:

naufragar 1 Hundirse o quedar destruida [una embarcación] mientras navega: el galeón español naufragó a causa de una tormenta (LEMA).

manar 1 Dicho de un líquido: Brotar o salir (DRAE).

empalagoso, sa 1 [Alimento] que empalaga por ser excesivamente dulce (DSAL).

frugal 1 Moderado o poco abundante, esp. referido a la comida (CLAVE). segar1 Cortar la $\rightarrow$ mies para su recolección (DEA).

trinchar Referido a la comida, partirla en trozos para servirla: Trincha $\underline{e l}$ asado y sirvelo en la salsa (CLAVE).

perpetrar Realizar un $\rightarrow$ delito: 'A la hora en que se perpetró el crimen' (DUE).

pagar Dar < una persona $>$ [una cantidad de dinero] [a otra persona] por una mercancía o un servicio (DSAL).

En este segundo tipo, los argumentos y, consiguientemente los contornos, constituyen "variables" que se instancian en el uso a través de unidades léxicas que satisfacen los requisitos semánticos exigidos por la entrada. Sin duda, podemos decir que hay aquí un 'hueco', una casilla que llenar, pero esta no está del todo vacía, como la de las entradas del primer tipo.

\section{TERCERO:}

Una cantidad relativamente importante de predicados de nuestro lexicón selecciona sus argumentos en virtud de una "clase léxica", no de un archilexema. El concepto se lo debemos a Bosque (2004), quien lo desarrolla y lo aplica con rigor en REDES. 
En los diccionarios semasiológicos de español, si bien no aparecen formuladas dichas clases léxicas, ellas "se adivinan" en los casos en que los contornos nos ofrecen listas de dos o más argumentos:

capcioso, sa 1 [Pregunta, argumento, razonamiento] que engaña o puede engañar porque está hecho con habilidad para confundir... (DSAL).

cumplir 2 Desempeñar o realizar [una función, un quehacer, una obligación] (DEA).

abolir Dejar sin vigencia una ley, precepto, costumbre, etc. (DRAE).

En capcioso, los nombres que se listan poseen en común el hecho de designar cierto tipo de 'manifestaciones verbales' de los seres humanos; en cumplir, el contorno presenta nombres que, en conjunto, pueden formar la clase de los "sustantivos que denotan tarea, generalmente asignada" (REDES, s.v., clase I); en abolir, por último, los nombres que se proporcionan en la definición pueden representar la clase de los "sustantivos que designan leyes y otras directrices estipuladas o reglamentadas" (REDES, s.V., clase A).

Pero, por el mismo hecho de que no se formulan las clases léxicas correspondientes, los elementos del contorno ofrecen un informe incompleto de los argumentos reales seleccionados por los definidos. En cumplir, por ejemplo, la clase admite, por definición, más sustantivos de los que DEA incorpora (i.e. cometido, papel, misión, rol, trabajo labor, etc.), lo mismo que en abolir (con la diferencia de que aquí la serie queda abierta gracias al etc. final), que, además de los anotados, acepta decreto, orden, norma, reglamento, constitución, etc.

Lo que queremos plantear, consiguientemente, es que, al no poder aparecer todos los argumentos que predicados como los descritos seleccionan, es preferible que se establezca una clase léxica semánticamente definida, como hace Bosque, y que a continuación se ingresen solo algunos miembros representativos de esa clase, ya que el listado no puede ser exhaustivo, por razones de espacio. Debe tenerse en cuenta además que, para cada unidad léxica, es posible formular más de una clase si se quiere dar debida cuenta de su comportamiento semántico-sintáctico. Consideremos, entre otros, el caso del verbo cumplir, que en REDES aparece descrito a través de 11 clases léxicas distintas (cada una con un número importante de argumentos).

\section{CUARTO:}

Finalmente, nos queremos referir a aquellos predicados que seleccionan unidades léxicas concretas, únicas, "consabidas", por así decir. Se trata de predicados cuyo número es poco significativo en el lexicón, quizás por resultar demasiado costoso al sistema lingüístico: 
torrencial 2 [Lluvia] muy intensa (DEA).

huero 1 [Huevo] que no produce cría, a pesar de haber sido incubado (DEA).

respingado, -a 1 a) Aplicado a la nariz, respingona (DUE) ${ }^{17}$.

encapotarse Referido al cielo, cubrirse de nubes oscuras (CLAVE).

repicar 1 Tocar [una campana] produciendo un sonido vivo y generalmente alegre (DEA).

guiñar 1 Cerrar un ojo momentáneamente quedando el otro abierto... (DRAE).

Como no existe aquí un 'clasema', un 'archilexema' o una 'clase léxica' de mayor extensión semántica, y como tampoco hay más de un elemento seleccionado por entrada, sostenemos que en casos como estos no puede afirmarse que los argumentos constituyan "huecos", debido a que las casillas abiertas por los respectivos predicados ya se encuentran ocupadas; en definitiva, creemos que no tiene sentido hablar, aquí, de variables argumentales.

Para concluir, diremos que, puesto que la selección argumental de las unidades predicativas del grupo III, que hemos establecido basándonos en las "restricciones léxicas" de Bosque (2004), se produce en términos semejantes a los observados en los grupos II y IV (el de las solidaridades de selección y de implicación, de Coseriu), el concepto de colocación, entendido como "combinación habitualizada de dos unidades léxicas", parece resultar inoficioso.

\section{SIGLARIO}

BBI: The BBI Combinatory Dictionary of English. A Guide to Word Combinations. Amsterdam, John Benjamins, 1997.

CCEC: Collins Cobuild English Collocations on CD ROM. A Comprehensive Database of Common Word Patterns from the Bank of English. Londres, Harper Collins, 1995.

CLAVE: Clave. Diccionario de uso del español actual, Madrid, ediciones SM, 2003.

DALE: Diccionario actual de la lengua española, Barcelona, Vox, 1990.

DEA: Diccionario del español actual, Madrid, Aguilar, 1999.

DEC: Dictionnaire explicatif et combinatoire du français contemporain, Recherches lexicosémantiques. Vol. 1 (1984), vol. 2 (1988), vol. 3 (1992), vol. 4 (1999), Les Presses de L'Université de Montréal.

17 En Chile, y tal vez en otras partes de América, respingada se dice solo de la nariz. En los diccionarios que hemos consultado, respingón puede referirse también a otras partes del cuerpo: culo respingón, nariz respingona (DRAE); trasero respingón (DEA). 
DICE: Diccionario de colocaciones del español. Proyecto dirigido por Margarita Alonso Ramos, Universidad de A Coruña

DICO: Dictionnaire de coocurrences, Montreal, Guerin, 2001.

DRAE: Diccionario de la lengua española, vigésima segunda edición, Madrid, Espasa, 2001.

DSAL: Diccionario Salamanca de la lengua española, Santillana, Universidad de Salamanca, 1996.

DUE: Diccionario de uso del español, Madrid, Gredos, 1966.

DUE: Diccionario de uso del español, Madrid, Gredos, 2002.

DVEHD: Diccionario del verbo español, hispanoamericano y dialectal, Herder, 2000.

GDLE 1: Gran diccionario de la lengua española, Madrid, Sgel, 1995.

GDLE 2: Gran diccionario de la lengua española, Madrid, Larousse, 2000.

LAF: Lexique active du français, en preparación. Universidad de Montréal.

LTP: Dictionary of Selected Collocations, Cengage Learning, 1997.

LEMA: Lema. Diccionario de la lengua española, Barcelona, Vox, 2001.

OCD: Oxford Collocations Dictionary for Students of English. Oxford University Press, 2002

REDES. Diccionario combinatorio del español contemporáneo, Madrid, Ediciones SM, 2004. 


\section{REFERENCIAS BIBLIOGRÁFICAS}

Abad Nebot, Francisco. 1997. Definición lexicográfica, diccionario y gramática. Homenaje al profesor A. Roldán Pérez, Tomo I, Universidad de Murcia.

Ahumada Lara, Ignacio. 1987. Contorno de la definición verbal y régimen lexemático: su indicación formal en la lexicografía hispánica. Amistad a lo largo. Estudios en memoria de Julio Fernández Sevilla y Nicolás Marín López, Universidad de Granada.

Alvar Ezquerra, Manuel. 1995. Cincuenta años de diccionarios monolingües. Vox, Cadernos de Lingua [A Coruña], anexo 3, RAG, pp. 65-85.

Alonso Ramos, Margarita. 1989. Aproximación a un nuevo modelo lexicográfico: el diccionario explicativo y combinatorio del francés contemporáneo. Anuario Galego de filoloxía, Vol. 16, Universidad Santiago de Compostela.

1994-5. Hacia una definición del concepto de colocación: de J. R. Firth a I. A. Mel'cuk. Revista de lexicografía I: 9-28.

2002. Colocaciones y contorno de la definición lexicográfica. LEA [Madrid], $\mathrm{XXIV} /$ 1: 63-96.

Apresjan, Juris. 1992. Lexical Semantics: User's guide to contemporary Russian vocabulary. Moscú: Karoma Publishers.

Bajo Pérez, Elena. 2000. Los diccionarios. Introducción a la lexicografía del español. Gijón: Trea.

Barrios Rodríguez, María. 2007. Diccionarios combinatorios del español: diferencias y semejanzas entre REDES y PRÁCTICO, Revista Electrónica de Didáctica ELE 11: $1-14$.

Bosque, Ignacio.1982. Más allá de la lexicalización. BRAE [Madrid], LXII: 103-158.

2001a. Bases para un diccionario de restricciones léxicas. Moenia 7: 11-52.

2001b. Sobre el concepto de 'colocación' y sus límites. LEA [Madrid] 1: 940.

2004. REDES, diccionario combinatorio del español contemporáneo. Madrid: Ediciones SM.

2005. La direccionalidad en los diccionarios combinatorios y el problema de la selección léxica, Linguistica teórica: análisi i perspectives, I, Universidad de Barcelona, pp. 13-58.

2006. Diccionario combinatorio PRÁCTICO del español contemporáneo. Madrid: Ediciones SM.

Сномsкy, NoAm. 1965. Aspects of the Theory of Syntax. Cambridge: MIT Press.

1986. Knowledge of language. Nueva York: Praeger.

Gutiérrez Cuadrado, Juan. (1994). Gramática y diccionario, Actas del Congreso de la lengua española, Sevilla. 
Hoyos Puentes, José y M. Belén Villar Díaz. 2006. Utilidad del diccionario contextual en la enseñanza del español a estudiantes franceses. En Bruña Cuevas et al. (eds.), La cultura del otro: español en Francia, francés en España, Sevilla.

López Martínez, Fernando. 2004. La delimitación de los argumentos en el proyecto de Estudio de las restricciones léxicas del Dr. Ignacio Bosque. En Paz Battaner y J. De Cesaris (eds.), De Lexicografia: Actes del I Symposium Internacional de Lexicografia, IULA, Barcelona.

Medina Guerra, Antonia María. 2003. Lexicografía española. Barcelona: Ariel.

MendikoetXea, Amaya. 2004. En busca de los primitivos léxicos y su realización sintáctica: del léxico a la sintaxis y viceversa. Contribución a la $2^{\circ}$ Xarxa Temática de Gramática Teórica, Universidad Autónoma de Madrid.

MeL'CuK, IGOR. 1989. Semantic primitives from the viewpoint of the Meaning-Text Linguistic Theory, Quaderni di Semantica 10, 1: 65-101.

1992. Paraphrase et lexique: la théory Sens-Texte et le Dictionnaire explicatif et combinatoire. En Igor Mel'cuk et al. Dictionnaire explicatif et combinatoire du français contemporain. Recherches lexico-sémantiques III, Les Presses de L'Université de Montréal, Montréal.

1997. Vers une linguistique Sens-Texte, Leçon Inaugural. Paris: Collègue de France, 139: 5-78.

MuÑIz, Eva María. 2005. Notas para unha análise comparativa das nocións de restricción léxica e colocación, Cadernos de fraseoloxía galega 7: 177-190.

Polguère, Alain. 2000. Towards a theoretically-motivated general public dictionary of semantic derivations and collocations for French, Proceedings of EURALEX' 2000, Stuttgart: 517-527.

Porto-Dapena, José Álvaro. 1980. Elementos de lexicografia: el Diccionario de construcción y régimen de R. J. Cuervo. Bogotá: Instituto Caro y Cuervo.

1988. Notas lexicográficas: la información sintáctica en los diccionarios comunes, LEA [Madrid], X/1: 133-151.

2002. Manual de técnica lexicográfica. Madrid: Arco/Libros.

Sanromán, Begoña. 2003. Semántica, sintaxis y combinatoria léxica de los nombres de emoción en español. Tesis inédita, Universidad de Helsinki.

Serra Sepúlveda, Susana. 2006. Gramática y diccionario. El problema del contorno en lexicografía española. Boletín de Filología de la Universidad de Chile, Tomo XLI: 197-240. 1: $119-149$.

Teso Martín, Enrique Del. 1997. En torno a la definición lexicográfica. Contextos 10, Universidad de León: 29-56. 